\title{
VIABILIDADE ECONÔMICA DE PROJETOS E ASPECTOS PARTICULARES EM EMPREENDIMENTOS TIPO PROJETO FINANCE APLICADOS A INVESTIMENTOS EM INFRAESTRUTURA DE TRANSPORTES
}

\author{
A. C. Pereira', O. Silveira Neto ${ }^{2}$ \\ 'DIETCON/CNAT - Instituto Federal do Rio Grande do Norte e ${ }^{2}$ Depto. Direito Privado/CCSA - UFRN \\ alexandre.pereira@ifrn.edu.br - otaciliosneto@yahoo.com.br
}

Artigo submetido em dezembro/2012 e aceito em janeiro/2013

\section{RESUMO}

O artigo tem por objetivo destacar aspectos relacionados com a análise da viabilidade de projetos de infraestrutura de transportes, aplicados a estudos de ampliação de capacidade de sistemas de transporte, sendo destacado no trabalho o aspecto da relevante importância da participação da iniciativa privada como parceira nos investimentos em infraestrutura. São abordados os métodos e estudos de viabilidade técnica e econômica, empréstimos, financiamentos e aspectos particulares a estudos para avaliação de projetos na área de infraestrutura de transportes. Como método para a avaliação de viabilidade financeira de projetos de concessões em investimentos em infraestrutura foi escolhido o Project Finance, tanto por seu potencial para a obtenção de parâmetros fundamentais para a tomada de decisão sobre alternativas de investimento, notadamente em projetos que considerem a participação privada como importante na viabilização do projeto, como para a análise de fatores intervenientes no risco de um investimento em obras de infraestrutura de transportes.

PALAVRAS-CHAVE: Infraestrutura, Parceria Público-Privada, Project Finance.

\section{ECONOMIC FEASIBILITY ASPECTS APPLIED ON PROJECT FINANCE INVESTMENTS ON TRANSPORT INFRASTRUCTURE}

\begin{abstract}
The article aims to show aspects of the feasibility analysis of transport infrastructure projects, studies applied to expand the capacity of transport systems, with particular attention to the question of the participation of the private sector in infrastructure investments. It runs on the methods and technical feasibility studies, economic, debt financing and private aspects of studies for the evaluation of projects in the field of transport infrastructure. As a method for
\end{abstract}

assessing the financial viability has chosen the Project Finance, for its potential for determining key parameters to support the decision process on alternative investments, mainly in projects that consider private participation as important for achieving the project and for the factor analysis usually involved in the risk of investment in transport infrastructure.

KEY-WORDS: Infrastructure, Public-Private Participation, Project Finance. 


\section{VIABILIDADE ECONÔMICA DE PROJETOS E ASPECTOS PARTICULARES EM EMPREENDIMENTOS TIPO PROJECT FINANCE APLICADOS A INVESTIMENTOS MEDIANTE PARCERIA PÚBLICO-PRIVADA EM INFRAESTRUTURA DE TRANSPORTES}

\section{INTRODUÇÃO}

O artigo apresenta como objetivo geral a apresentação de aspectos relacionados à temática do estudo da viabilidade socioeconômica em investimentos em infraestrutura de transportes, possuindo como objetivo específico a apresenta conteúdos sobre estudos relacionados com a análise da viabilidade de projetos de infraestrutura de transportes, aplicados a estudos de ampliação de capacidade de sistemas de transporte, sendo destacado no trabalho o aspecto da relevante importância da participação da iniciativa privada como parceira nos investimentos em infraestrutura. São abordados os métodos e estudos de viabilidade técnica, econômica e econômica, empréstimos, financiamentos e aspectos particulares a estudos para avaliação de projetos na área de infraestrutura de transportes.

\section{METODOLOGIA}

No trabalho de pesquisa que conduziu ao trabalho foi utilizada a metodologia de pesquisa bibliográfica, conhecer os elementos normativos, métodos e parâmetros a considerar na atividade da avaliação financeira de projetos de infraestrutura de transportes, em especial os relacionados ao modal rodoviário. Fundamentalmente, serão estudados elementos relacionados com previsões de tráfego e os conseqüentes benefícios sociais e econômicos da obra, essenciais, por exemplo, para a estimativa da demanda e montagem do fluxo de caixa decorrente do projeto, muito importantes, respectivamente, para obras financiadas com recursos oriundos dos cofres públicos e para ações do tipo Parcerias PúblicoPrivadas para construção e operação de infraestruturas de transportes.

Como método para a avaliação de viabilidade financeira de projetos de concessões em investimentos em infraestrutura foi escolhido o Project Finance, tanto por seu potencial para a obtenção de parâmetros fundamentais para a tomada de decisão sobre alternativas de investimento, notadamente em projetos que considerem a participação privada como importante na viabilização do projeto, como para a análise de fatores intervenientes no risco de um investimento em obras de infraestrutura de transportes.

\section{ANÁLISE DE VIABILIDADE DE PROJETOS DE GRANDE VULTO: A PRÁTICA GOVERNAMENTAL}

\section{Sobre a Prática Governamental na Análise de Projetos}

Segundo Dalbem et al. (2010), no Brasil, embora já existam algumas normas e diretrizes que levam em consideração os efeitos do melhor acompanhamento e questionamento por parte da sociedade quanto à melhor forma de investir recursos escassos, fazendo frente ao desafio de transformar os potenciais benefícios econômicos de um projeto de transportes em valores tangíveis, não há ainda uma cultura consolidada nesse sentido, tampouco um conjunto de práticas definidas para o uso da avaliação econômica como 
ferramenta de decisão de investimentos públicos. Comenta ainda que na avaliação financeira, procura-se identificar se o projeto é autossustentável financeiramente, enquanto na avaliação econômica o foco é definir se o projeto gera benefícios líquidos para a sociedade, entendidos como os benefícios incrementais causados pelo projeto. Dessa forma, em projeto que capture demanda já atendida por outros meios, deve ser considerado apenas o seu benefício adicional para a sociedade e não a demanda total atendida.

Dalbem et al. (2010) reforça outro importante conceito em avaliação econômica referente às externalidades, entendidas, segundo o conceito empregado pelo WBH (1996), como os impactos causados a terceiros, pelos quais o projeto não está sendo onerado ou, ainda, beneficiando a terceiros (segurança, por exemplo), o que não geraria receita para o projeto. Destaca que o Banco Mundial recomenda que essas externalidades sejam quantificadas monetariamente sempre que possível, sendo importante definir os principais critérios de avaliação econômica para tal. Comenta que o critério cost-benefit analysis (CBA) analisa alternativas de investimento via quantificação monetária do maior número possível de custos e benefícios, sendo no caso das externalidades, tal quantificação monetária efetivada usualmente mediante métodos como os de valoração contingente, que procuram determinar a disposição dos usuários para pagar (willingness to pay - WTP) por um determinado item ou serviço. Quando não há como monetizar todos os efeitos de um projeto, uma alternativa é usar o critério de custo-efetividade, ou cost effectiveness analysis (CEA).

Por esse critério, cita, os benefícios são ainda quantificáveis, porém, por meio de outros resultados como, por exemplo, quantas pessoas ou empresas, hoje não atendidas, passarão a usufruir da nova infraestrutura. Tais benefícios, comenta, ponderados pelo custo total do projeto, tornam possível ordenar projetos alternativos por ordem de efetividade. Embora seja um bom critério para escolher entre alternativas, o CEA não contribui para a decisão investir/não investir (World Bank, 2005).

Quando existem múltiplos objetivos a serem atingidos em um projeto, Dalbem et al. (2010) destaca que uma terceira alternativa é usar análise multicritério (MCA, em inglês), bem detalhada no trabalho de Dogson et al. (2001). Na MCA, comenta Dalbem et al. (2010) que os diversos objetivos são ponderados por sua importância relativa, gerando uma nota que, dividida pelo custo do projeto, produz um índice que permite a comparação com outros projetos.

A atribuição desses pesos pode ser transparente, na medida em que especialistas e a população sejam chamados a opinar, porém um forte componente de subjetividade continuará sempre existindo nesse processo. Quando os objetivos finais do projeto não forem facilmente quantificáveis, acrescenta, resta a análise qualitativa, embora restringir a avaliação econômica a dados qualitativos pode aumentar muito a subjetividade, a ponto de afetar a transparência e a imparcialidade da análise.

Finalmente, cita Dalbem et al. (2010) o trabalho de Grant-Muller et al. (2001), que apresenta como se tem feito avaliação econômica, na prática, em 14 países europeus, para a definição de prioridades em projetos (não como elemento decisão final), reconhecendo, entretanto, que outros fatores (fundamentalmente políticos e culturais) devem ser também 
levados em consideração na decisão final. Comenta que este fato dificulta a uniformização de práticas na Europa e representa um desafio especialmente naqueles projetos cujos impactos transcendem as fronteiras nacionais.

O Banco Mundial (2005) também alerta que o CBA ainda não incorpora desenvolvimento econômico, emprego, redução de pobreza, na análise, sugerindo que o CEA seja usado para uma primeira triagem dos projetos, escolhendo apenas os que atendam aos objetivos de difícil monetização. Em uma segunda fase, comenta, uma análise CBA identificaria os projetos considerados como economicamente viáveis.

\section{Análise de Projetos no Setor de Transportes}

Sobre a questão da decisão a ser tomada para a priorização de alternativas de investimento, o PNLT (Plano Nacional de Logística e Transportes), dispõe que a análise do desempenho das alternativas de investimento em infraestrutura de transportes em estudo, será realizada após a definição dos agrupamentos dos projetos de investimento, mediante a realização de simulações das alternativas propostas para a eliminação dos gargalos e a consolidação dos resultados obtidos. Inicialmente é feita a simulação da alternativa base, ou seja, a alternativa na qual nenhuma intervenção é implementada durante o período de análise (alternativa "fazer nada"). Em seguida são realizadas simulações para cada avaliar o impacto da introdução das intervenções referentes a uma determinada alternativa.

Os resultados das simulações permitem a determinação dos benefícios obtidos com a implantação do projeto ou grupo de projetos e a priorização das alternativas simuladas em função dos benefícios estimados. Na simulação da alternativa base, a alocação do tráfego para a avaliação do projeto consiste na alocação da demanda, representada pelas várias matrizes de fluxos dos diferentes produtos, em diferentes anos-horizonte, dentro do período de estudo.

O principal produto desta atividade consiste na caracterização do desempenho atual de cada uma das ligações que compõem a rede nacional multimodal de transporte. $O$ indicador a ser utilizado para a avaliação do desempenho da rede será a razão Volume/Capacidade relacionado a cada ligação. O mapeamento desta informação permitirá a visualização dos pontos críticos da rede. Tendo sido definidas as matrizes de viagem dos diversos produtos, nesta sub-atividade foi realizado o carregamento da rede base com as matrizes referentes a cada um dos anos horizonte de maneira que seja possível não apenas localizar trechos com níveis de serviço inadequados, mas também identificar o horizonte temporal em que tais ligações deverão receber intervenções de aumento de capacidade.

$\mathrm{Na}$ simulação das alternativas futuras, tendo sido propostas as intervenções para aumento de capacidade das ligações da rede multimodal de transporte referente à situação base, após o cadastramento dos diversos projetos de ampliação de capacidade na rede de simulação, realizados novos carregamentos com as matrizes projetadas para os diversos anoshorizonte, se obtém resultados que geram os insumos necessários para a realização do estudo de viabilidade sócio-econômica das intervenções propostas. Na fase da avaliação das alternativas será realizada a classificação dos projetos em função de suas prioridades para 
solução dos gargalos e elos faltantes referentes aos horizontes de curto, de médio e de longo prazos.

O benefício para os usuários é calculado para cada tipo de fluxo, em termos monetários e de tempo, considerando-se a implantação de uma alternativa que reduz o custo generalizado de transporte para o usuário para um dado par de zonas. O custo generalizado do transporte para o usuário corresponde à tarifa média ou o preço médio que ele paga, mais o tempo gasto (avaliado monetariamente), para transportar a si ou ao seu produto da zona de origem para a de destino, pelas várias modalidades de transporte disponíveis.

Quanto ao modelo de avaliação sócio-econômica do projeto, geralmente é definido segundo a fundamentação nos conceitos da análise custo/benefício, o qual permite calcular os indicadores tradicionais de estudos de viabilidade econômica, mais especificamente, a Taxa Interna de Retorno Econômico (TIRE) e Valor Presente Líquido (VPL). Com as informações sobre os benefícios econômicos e os investimentos necessários relativos a cada ano horizonte, pode ser estabelecido o fluxo de caixa relativo a cada empreendimento. Estes elementos permitem o cálculo de indicadores de eficiência econômica como a Taxa Interna de Retorno ou outros, para cada caso considerado. Mediante a priorização das alternativas de investimento, com base em critérios de decisão adequados em função dos objetivos pretendidos, é realizada a montagem do portfólio, contendo todos os investimentos em termos de alternativas ou outras intervenções, caracterizados e mapeados.

Finalmente, com base nos resultados do processo de priorização das alternativas, o Portfólio será reorganizado segundo propostas priorizadas, estabelecendo um cronograma de implementação ao longo do tempo, estruturando-o para o período horizonte do projeto.

\section{ANÁLISE DE INVESTIMENTOS EM INFRAESTRUTURA DE TRANSPORTES MEDIANTE PROJECT FINANCE}

\section{Características do Método}

Project Finance é uma forma de engenharia financeira sustentada contratualmente pelo fluxo de caixa de um projeto, que serve como garantia à referida colaboração os ativos desse projeto a serem adquiridos e os valores recebíveis ao longo do projeto. Os contratos de Project Finance são baseados na análise e quantificação dos riscos envolvidos, cujo objetivo básico é o de prever qualquer variação no fluxo de caixa do projeto, minimizando os riscos através de obrigações contratuais. Trata-se de uma modalidade de apoio mais comum a projetos de grande porte, normalmente para o setor de infra-estrutura, tais como usinas, estradas, projetos de saneamento básico e outros.

Para os investidores ou patrocinadores, o Project Finance ainda oferece o atrativo do modelo non recourse, que limita sua responsabilidade aos capitais aportados, sem direito de regresso (Borges, 2006). Especialmente para os países do chamado Terceiro Mundo e, particularmente, referindo-se a regiões destes países afetadas por depressão econômica, o estudo de alternativas para financiamentos em investimentos em projetos de infraestrutura 
possui relevante importância quando se buscam meios para promover o crescimento econômico e o desenvolvimento dessas regiões.

Convém que se ressalte a tendência mundial referente à progressiva limitação dos Estados em promover a participação de recursos públicos no financiamento de obras de infraestrutura. No Brasil, a década de 1970 pode ser considerada foi a última caracterizada pela expansão da participação do Estado na economia, mesmo utilizando recursos privados internacionais.

\section{Parcerias Público-Privadas}

Diante da necessidade de alternativas para a resolução do problema da escassez de recursos estatais necessários ao desenvolvimento da deficitária infraestrutura brasileira, é instituída pela Lei Federal n.ㅇ 11.079, de 30 de dezembro de 2004, a figura da Parceria Público-Privada (PPP). Trata-se de um mecanismo que visa a maximização da atração do capital privado para a execução de obras públicas e serviços públicos por meio de concessão, bem como para a prestação de serviços de que a Administração Pública seja usuária direta ou indireta, suprindo a escassez de recursos públicos para investimentos de curto prazo. A expressão Parceria Público-Privada, do inglês Public Private Partnership, indica a atração de investimentos privados para projetos tradicionalmente delegados ao Estado, mediante princípios, por exemplo, de Project Finance.

No Brasil, a Parceria Público-Privada surgiu estruturalmente da experiência e do pioneirismo bem sucedido do modelo de Project Finance, mecanismo utilizado para a concepção de diversos projetos para o desenvolvimento de infraestruturas de transporte. 0 consenso da comunidade financeira internacional parece ver no uso do Project Finance o novo instrumento que permitirá conseguir investimentos em infra-estrutura para países do Terceiro Mundo, onde não há oferta, ou otimizar esses recursos, onde ela existir. Essa visão vem ganhando corpo entre os agentes financeiros e, somada aos volumes extraordinários exigidos pelo setor de infra-estrutura, torna imperiosa a discussão do que significa operar na modalidade Project Finance, quais as suas vantagens e limites.

Em decorrência desse novo entendimento, surgiu uma divisão importante sobre como se proceder a uma análise desse tipo de projeto: por um lado, há a análise tradicional, baseada na capacidade de um tomador de empréstimo em pagá-lo, em suas demonstrações financeiras e nas garantias (preferivelmente reais) oferecidas, que passam a fundamentar, no setor bancário, uma colaboração financeira corporativa (e garantias corporativas); e, por outro, o Project Finance, ou a estruturação de um financiamento relacionado ao projeto, centra a análise no projeto em si, isolando seus ativos do risco do empreendedor ${ }^{1}$.

\footnotetext{
${ }^{1}$ Na realidade, o Project Finance é mais do que isso, pois se trata de uma engenharia de projeto estruturado para segregar o risco, preservar a capacidade de endividamento de seus empreendedores ou patrocinadores, dividir o risco entre vários interessados, economizar no pagamento de tributos, levar adiante um projeto grande demais para um só patrocinador ou evitar a necessidade de garantias reais, utilizando apenas a garantia de recebíveis do próprio projeto, ou seja, mediante o fluxo de caixa autogerado.
} 


\section{Análise de Investimentos Project Finance}

Primeiramente, há que se reforçar que em um método de avaliação de viabilidade econômico-financeira tipo Project Finance, fundamentalmente, a decisão sobre a realização do investimento se centra na possibilidade de geração de recursos pelo próprio projeto. Segundo Izquierdo e Vassallo (2005), consiste em característica básica de um Project Finance a particularidade de que o titular dos ativos do projeto será representada por uma sociedade com personalidade jurídica independente (SPE: Sociedade para Propósito Específico), independente da pessoa jurídica dos promotores do projeto, que atuará como a concessionária. $\mathrm{O}$ risco dos patrocinadores se limita ao aporte de capital realizada, ocorrendo geralmente endividamento e alavancagem elevados, bem como o desequilíbrio temporal do projeto, que requer forte inversão inicial e relativamente longo período de maturação.

Assim, em um projeto de investimento mediante o método Project Finance são mobilizados diversos agentes, constituindo um sistema que apresenta a Sociedade para Propósito Específico (SPE) como o elo de ligação entre os componentes do conjunto de agentes constituído, conforme apresenta esquematicamente a Figura 01.

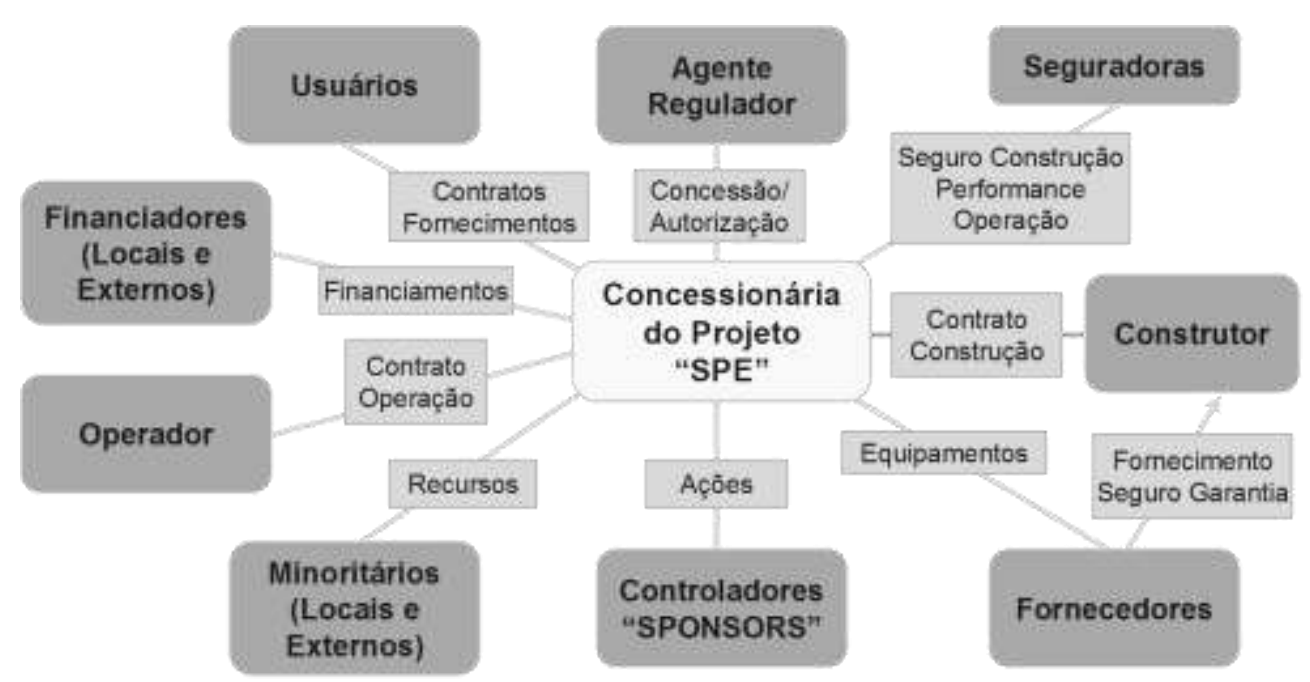

Figura 01: Estrutura de um Project Finance (adaptado de Izquierdo e Vassallo, 2005).

Convém destacar que o desenvolvimento satisfatório do projeto dependerá, em grande parte, da adequada definição da relação entre os agentes constituintes do projeto, notadamente durante o decorrer do desenvolvimento do mesmo, tendo em vista que adequações são inexoravelmente necessárias com o passar do tempo, mesmo quando as condições se apresentem como ótimas no começo da implementação do projeto ${ }^{2}$.

\footnotetext{
${ }^{2}$ É importante que se destaque, também, a necessidade de contínuo monitoramento por parte do Estado dos parâmetros de desempenho do projeto, para sejam devidamente avaliada se estão sendo adequadamente atendidos/satisfeitas as necessidades dos usuários, como também mantido o equilíbrio econômico-financeiro do contrato de concessão, segundo uma visão de sustentabilidade do empreendimento, essência dos projetos de investimento em infraestrutura mediante parcerias público-privadas.
} 
Segundo Izquierdo e Vassallo (2005), a estrutura do método Project Finance, necessária para a implementação de investimentos, possuirá basicamente modelo econômico-financeiro que compreenda uma série de premissas com natureza técnica, financeiro-tributárias e de mercado que sejam capazes de promover a adequada aplicabilidade do método em função das diversas condições impostas pelas citadas premissas que, mediante o processamento dos correspondentes dados de entrada no modelo (inputs), conduzam a resultados (outputs) que viabilizem informações sobre fluxo de caixa, análise de sensibilidade e sobre eventual necessidade de contraprestação por parte do Poder Público, imprescindíveis para a adequada avaliação do risco e conseqüente viabilidade econômicofinanceira do projeto, conforme procura mostrar a Figura 02 apresentada a seguir.

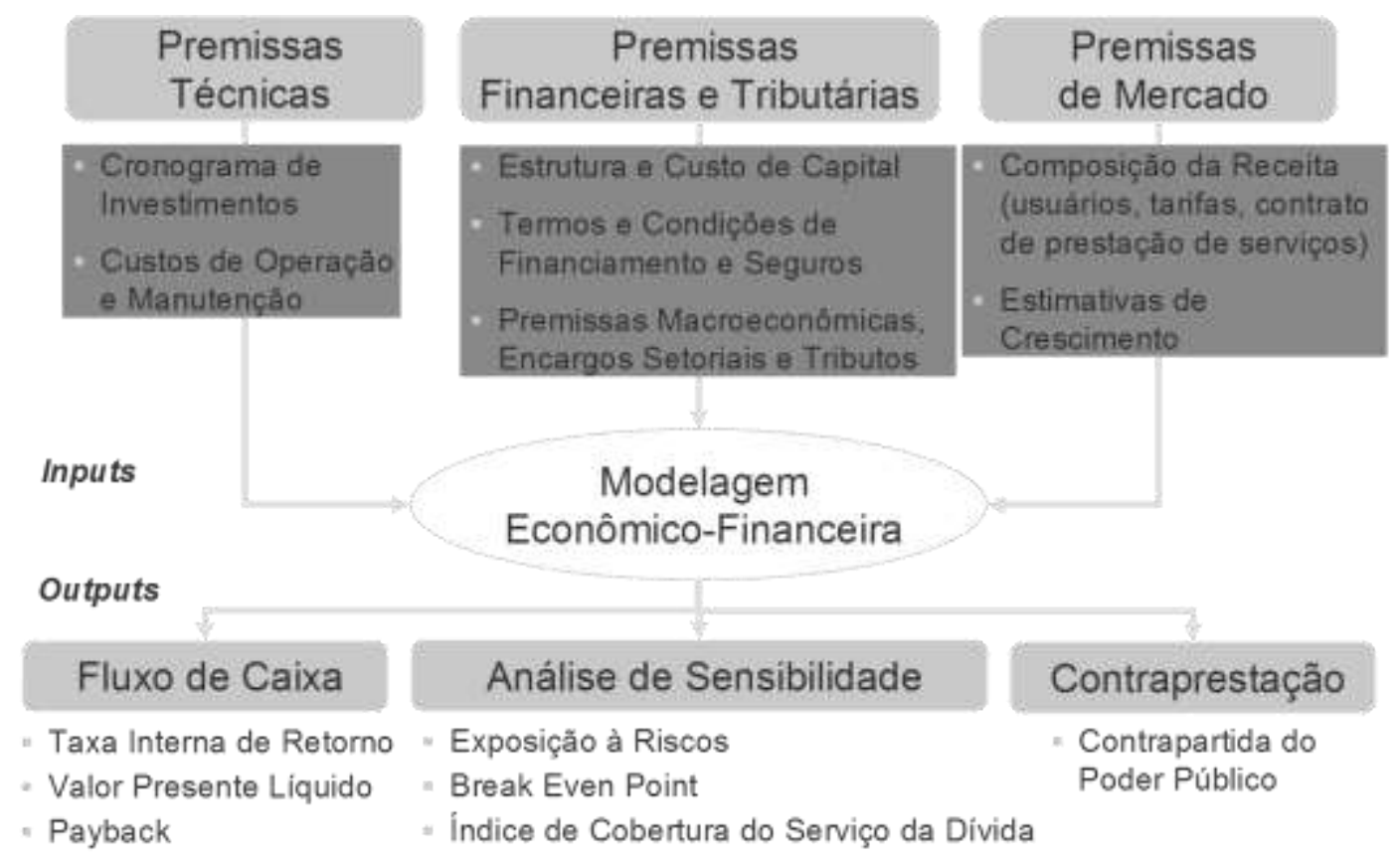

Figura 02- Modelagem de um Project Finance (adaptado de Izquierdo e Vassallo, 2005).

\section{Avaliação do Risco do Projeto}

Sobre a questão da negociação da estrutura do financiamento na modalidade Project Finance, Izquierdo e Vassallo (2005) destacam que na composição recursos próprios + recursos externos que integram o investimento o tratamento dado ao fluxo de caixa livre é essencial para a adequada avaliação do risco do projeto, conforme expõem no trecho destacado a seguir:

"O investidor, em projetos elaborados mediante a modalidade Project Finance, deverá adotar mecanismos de proteção frente aos riscos no projeto que sejam capazes de avaliar convenientemente a importância da volatilidade (incerteza) do fluxo de caixa livre, exigindo determinadas coberturas que funcionem para garantir 
suficientemente a normal devolução do empréstimo. Um maior risco no projeto implica no maior encarecimento do mesmo, com um correspondente ônus para a sociedade que, no final, tanto atua como o beneficiário do projeto como a parte que será responsável pelo pagamento de uma maior tarifa ou, de outra forma, mediante o aporte de recursos públicos ou subvenções".

A teoria clássica sobre o estudo da alocação de riscos considera que estes devam cair sobre os agentes que podem controlá-los melhor. Nesse sentido, o controle de risco é distinto para um agente com o domínio sobre o risco que por outro agente sem possibilidade de gerenciamento sobre o risco.

Admite-se que um agente tem algum controle sobre uma determinada variável quando o esforço é determinante para o desfecho, independentemente se o resultado final seja, de antemão, incerto. Por exemplo, é evidente que uma empresa de construção não é capaz de saber exatamente, antes de iniciar o trabalho, o custo final dessa obra. No entanto, independentemente de a empresa não ser capaz de estimar o custo final, em função do grau de organização e eficiência, se o trabalho não está sujeito a incertezas significativas de características geológicas e climáticas, em seu custo final, o risco será controlável pelo agente.

Considerando o financiamento de um projeto de investimento em infraestrutura composto pela composição de capital próprio acrescido de dívida, para a valoração do risco do projeto por parte dos agentes de crédito é realizada, no modelo Project Finance, a divisão da dívida em duas componentes: Dívida Sênior e Dívida Subordinada. Convém que se destaque que a adequada definição dos riscos no projeto, associada à clara atribuição de responsabilidades para fazer frente aos mesmos e ao suficiente aporte de capital por parte de patrocinadores do projeto, consistem em elementos fundamentais para que se obtenham razões de cobertura para a dívida que propiciem a sustentabilidade e rentabilidade do projeto. Assim, a adequada avaliação dos riscos do projeto consistirá em importante condição para que se conduza ao equilíbrio econômico-financeiro do investimento. Para que os riscos do projeto sejam avaliados convenientemente, é importante destacar o papel da qualificação creditícia (rating) no projeto e o grau de comprometimento dos patrocinadores com o mesmo (participação do capital privado no investimento), sem esquecer da questão referente à avaliação da solvência dos patrocinadores.

\section{A Questão da Transferência de Riscos}

Conforme comenta Allen $(2003)^{3}$, a transferência de risco em projetos de investimento mediante recursos privados (PFI: Private Finance Initiative), tal como acontece com muitos outros tipos de PPPs, é realizada para transferência do riscos do setor público para o setor privado, o que é percebido como sendo uma oportunidade para administrar o risco. Riscos que podem ser transferidos para o setor privado podem ser divididos em dois grupos: riscos comuns a todos os tipos de projeto (público e privado) e riscos que são específicos de projetos $\mathrm{PFI}$ ou específicos a serviços públicos. Riscos específicos a projetos PFI se apresentam segundo muitas formas e dependem das características de um determinado projeto.

\footnotetext{
${ }^{3}$ Ver ALLEN, G. (2003): Research Paper 03/79. Ed. House of Commons Library. London. HOLOS, Ano 28, Vol 6
} 
Os riscos envolvidos na manutenção de um pátio de escola a certeza de diferir dos riscos associados ao projeto de transporte em larga escala. A transferência de riscos em serviços públicos é diferente em contratos do tipo $\mathrm{PFI}$, o que permitiu a transferência de risco e financiamento de projetos para o do sector privado. O principal benefício da transferência do risco financeiro do setor privado é que o ato poderá ser percebido como tendo uma alternativa para o setor público fazer frente aos com riscos financeiros. Em um projeto de financiamento dos serviços públicos de risco, o risco de entregar um pacote financeiro economicamente viável, pode ser dividido em dois tipos principais: risco interno e risco externo de financiamento. O risco interno (disposal risk) é o relacionado ao risco onde o valor esperado pelo órgão público, em um contrato de PFI para financiar os serviços públicos, é menor do que o esperado. Risco de financiamento externo é o risco referente à dificuldade que o contratante de financiamento do setor privado possui em conseguir levantar no mercado suficiente capital para um projeto de serviços públicos.

Segundo Allan (2003), a transferência do risco do projeto de financiamento gera incentivos para o setor privado de prestação de serviços, no prazo certo e em uma qualidade superior, pois só começam a receber pagamentos do serviço quando se inicia o fluxo de ingressos de serviços públicos. Também a sustentabilidade nos pagamentos depende de critérios de desempenho específicos. Um efeito adicional da transferência do risco de financiamentos de um projeto para o setor privado, comenta, é a redução de riscos gerais de projetos acumulados pelo setor público. Contudo, o risco e a recompensa andam de mãos dadas: quanto maior o risco percebido que está sendo transferido é o setor privado, maior o prêmio de risco exigido pelo contratante do setor público para compensar a sua exposição. Dado que alguns riscos são difíceis de quantificar, é difícil determinar se um contratante do setor privado, para aceitar um risco particular, está cobrando um prêmio de risco adequado.

Convém destacar, conforme comentado por Delfour (2010), que a abordagem da dívida mediante projetos de infra-estrutura tipo Project Finance aplica-se quando o reembolso depende dos fluxos de caixa a partir da construção, operação e, em alguns casos, a entrega um projeto independente (que pode incluir diversos ativos em lugares diferentes). Primeiramente, em função da análise do potencial de um projeto para gerar um fluxo de caixa estável, tendo em conta os fundamentos jurídicos e econômicos, bem como os riscos políticos e macroeconômicos da região de influência do projeto. Posteriormente, a consideração sobre a estrutura financeira, a fim de formar uma posição consolidada quanto à capacidade dos fluxos de caixa para atender às obrigações de dívida.

Ao analisar um projeto, consideram fatores como os fundamentos do projeto, o patrocinador e a estrutura jurídica, e o risco de extinção, risco tecnológico, risco operacional e de manutenção, bem como os riscos para projetar as receitas brutas do volume, preço ou disponibilidade. A alocação de riscos é um fator chave no financiamento de projetos, de modo que deverá se avaliado o seu impacto sobre a SPE, conforme cada fator de risco que, na maioria dos casos, incluem um nível mínimo de qualidade de crédito compatível à importância do risco associado.

Quanto à questão da alocação ótima de risco, uma vez que os riscos associados com um projeto tipo PF têm sido identificados, a próxima tarefa é a definição do 
compartilhamento dos riscos entre os parceiros públicos e privados. O reconhecimento pelo Governo do princípio que "o risco deve ser alocado para quem é capaz de melhor gerenciá-lo" é fundamental. O Quadro 01, apresentado por TRC $(2007)^{4}$, mostrado a seguir, apresenta uma visão geral sobre como cada espécie de risco deverá ser alocada aos correspondentes entes públicos e privado. Como regra geral, portanto, em regimes PFI os riscos de projeto, construção e operação (custo e desempenho) devem sempre ser transferidos para o fornecedor. Demanda e outros riscos devem ser objeto de negociação.

Entretanto, uma questão, todavia, persiste: Como devem os riscos ser alocados? A resposta convencional, de que cada risco deve ser alocado para a parte mais capaz de gerenciá-lo parece ser certa, mas é demasiado vaga para ser muito útil por si só. O princípio, proposto por Irwin (2007), na intenção de esclarecer a questão, é que cada risco deve ser atribuído, juntamente com o direito de tomar decisões relacionadas, de modo a maximizar o valor total do projeto, tendo em conta a capacidade de cada uma das partes em influenciar sobre o fator de risco correspondente, de influenciar a sensibilidade do valor total do projeto para o correspondente fator de risco (por exemplo, ao antecipar ou responder ao fator de risco) e em absorver o risco propriamente dito.

Quadro 01: Atribuição hipotética aos riscos em projetos típicos de infraestrutura ${ }^{5}$.

\begin{tabular}{|l|l|l|}
\hline \multicolumn{1}{|c|}{ Categoria de Risco } & \multicolumn{1}{|c|}{ Exemplo } & Parceiro Responsável pelo Risco \\
\hline Força Maior & $\begin{array}{l}\text { Perdas por desastres naturais ou } \\
\text { guerra }\end{array}$ & Público \\
\hline Risco Político / Regulatório & $\begin{array}{l}\text { Demora na aprovação de projetos } \\
\text { e processos de indenização, } \\
\text { alteração na lei e instabilidade } \\
\text { política }\end{array}$ & Público \\
\hline Risco de Demanda & $\begin{array}{l}\text { Previsão tráfego } \\
\text { superestimada e/ou ingressos } \\
\text { inferiores ao esperado devido à } \\
\text { elasticidade de demanda }\end{array}$ & $\begin{array}{l}\text { Geralmente Público - Podendo } \\
\text { também ser Privado }\end{array}$ \\
\hline Risco Técnico & $\begin{array}{l}\text { Deficiências de projeto } \\
\text { relacionadas com soluções de } \\
\text { engenharia }\end{array}$ & Privado \\
\hline Risco de Construção & $\begin{array}{l}\text { Custos devido a falhas e demoras } \\
\text { durante a construção }\end{array}$ & Privado \\
\hline Risco de Operação & $\begin{array}{l}\text { Custos de operação e manutenção } \\
\text { mais elevados que o esperado }\end{array}$ & Privado \\
\hline Risco Ambiental & $\begin{array}{l}\text { Custos de danos } \\
\text { responsabilidade ambiental }\end{array}$ & Privado \\
\hline Risco Financeiro & $\begin{array}{l}\text { Custos oriundos de administração } \\
\text { inadequada da dívida }\end{array}$ & $\begin{array}{l}\text { Geralmente Privado - Podendo } \\
\text { também ser Público }\end{array}$ \\
\hline Risco de Falha de Projeto & $\begin{array}{l}\text { Ruptura de projeto por qualquer } \\
\text { dos fatores elencados acima }\end{array}$ & Compartilhado Público / Privado \\
\hline
\end{tabular}

\footnotetext{
${ }^{4}$ Ver TRC (2007): Transport Infaestructure Investment: Options for Efficiency. Summary Document. Ed. OECD/ITF.

${ }^{5}$ Convém destacar que não há como generalizar com exatidão como deverão os riscos ser atribuídos às partes, o que pressupõe ser estritamente necessária a devida análise em conformidade com cada natureza de projeto. Esta postura é essencial para o reconhecimento de que o parceiro privado será adequadamente compensado financeiramente para cada risco atribuído à sua responsabilidade.
} 
Izquierdo e Vassallo (2002) comentam que a rigor a maioria das variáveis que são manipuladas em um projeto são incertas e é praticamente impossível determinar, pelo menos com precisão, as funções de probabilidade que regem as variáveis aleatórias de um projeto. Embora seja verdade que, intuitivamente ou com base em experiências anteriores em circunstâncias semelhantes, seja possível ter uma idéia de que intervalo de variação pode mover uma determinada variável, destacam que, na prática, é muito difícil separar o risco controlável do não-controlável pelo revendedor.

Por exemplo, quando um custo adicional para a construção vai ser muito difícil de avaliar, do ponto de vista de um observador de fora, se a ultrapassagem dos custos deveu-se a causas imputáveis à concessionária (por exemplo, uma organização inadequada do trabalho) ou sem culpa para ele (por exemplo, uma temporada de chuvas inesperadas, etc.).

Isto significa que, na prática, ser muito difícil separar os riscos sobre os quais o operador tem controle, daqueles em que ele não tem, o que dificulta o estabelecimento de uma cláusula contratual que os separa. Em segundo lugar, a estrutura da indústria tradicional é muito mais flexível para produzir bens diferentes, que podem permitir uma maior diversificação do abastecimento em tempos de crise.

No entanto, nas concessões de infraestrutura, os custos de investimento inicial têm características de custos irrecuperáveis, ou seja, custos que são pagos uma vez, por pouco recuperável que sejam para outras atividades. Por exemplo, enquanto uma fábrica pode ser usada para produzir um ou outro produto, até a construção pode ser vendida para outro uso, investimentos como uma infraestrutura viária será utilizada para pouco mais do que fazer transportar veículos, bens e pessoas. Em terceiro lugar, enquanto a indústria tradicional pode definir livremente seus preços, as concessões de obras públicas aplicam, na maioria dos casos, taxas fixadas pelos termos do contrato, não podendo variá-las de acordo com certas circunstâncias temporárias.

Em resumo, pode-se concluir a discussão apontando algumas idéias: primeiro, as concessões de obras públicas estão necessariamente sujeitas a riscos significativos que não podem ser removidos, mas absorvidos, em segundo lugar, atribuir os riscos a cargo dos agentes o que tem melhor capacidade de controle, em terceiro lugar, muitos riscos são difíceis de controlar pelo concessionário (especialmente o risco de tráfego) e, em quarto lugar, a estrutura das concessões, com custos fixos significativos e custos irrecuperáveis, tornam especialmente adaptáveis à pouca flexibilidade para responder às flutuações cíclicas do risco de demanda, o que justifica, em certa medida a tomar medidas adequadas para reduzir esse risco.

\section{Elementos Determinantes do Custo da Dívida}

Segundo Izquierdo e Vassallo (2005), os elementos constituintes do custo da dívida são definidos pela somatória do custo do financiamento com os correspondentes valores da margem para financiar os custos operativos e o prêmio pelo risco assumido (spread), conforme expõem no trecho destacado abaixo: 


\begin{abstract}
"Para a determinação do prêmio pelo risco é realizado o cálculo da perda esperada (expected loss), que se determina geralmente mediante o método da simulação do fluxo de caixa livre. A utilização do método de Monte Carlo para o tratamento das variáveis segundo tratamento probabilístico representa uma opção para o estudo da perda esperada mediante simulação do fluxo de caixa livre, embora consista em modelização complicada para a definição de funções de probabilidade que representem o comportamento das variáveis custo, prazo de construção, tráfego...".
\end{abstract}

Portanto, na intenção de tornar a modelização da determinação do prêmio pelo risco realizado mediante o cálculo da perda esperada (expected loss) menos complicada, se recorre à análise de sensibilidade pelo emprego de modelo simplificado que não considera aquelas garantias geradas no projeto que resultam de difícil modelização.

O modelo simplificado que é usualmente utilizado consiste em tratamento estatístico mediante análise de histograma que considerem o número de casos que estejam incluídos em determinado nível de perdas para os credores, o que conduzirá à determinação da função de densidade de perda para a entidade financeira e, consequentemente, à avaliação do risco do projeto sob a ótica dos agentes financeiros envolvidos.

\title{
A Garantia em um Project Finance
}

Quanto à garantia em um investimento na modalidade Project Finance, destacam Izquierdo e Vassallo (2005) que o projeto em si mesmo representa a maior garantia do investimento, o que conduz à particular característica da modalidade de financiamento no qual a expectativa de ingressos (fluxo de caixa esperado) representa o fator primordial na análise de viabilidade do projeto. Convém que se destaque, ainda, que na modalidade Project Finance caberá ao Estado o direito de resgatar a titularidade da concessão caso o nível de desempenho dos serviços prestados à população não atenta satisfatoriamente a determinados padrões de qualidade.

Conforme comenta Delfour (2010), garantias para o credor podem se manifestar na forma de redução da probabilidade de default da dívida nominal ou de perdas em caso de inadimplência. Nos casos em que se permite a ampla concorrência, a disponibilidade de garantias (ativos financeiros, expertise financeira e intelectual) aos detentores de dívida é considerada como convencional. Segundo o seu entendimento, um amplo acordo entre os credores, no objetivo de limitar o alcance em relação às ações preventivas e definir a classe de controle do credor, antes da implantação das medidas, pode reduzir a incerteza sobre os ativos do projeto em períodos adversos. Acrescenta que grande parte desta garantia também se apóia sobre a existência de uma jurisdição confiável e amigável para os credores, sendo também desejável a disponibilidade de controle sobre as receitas de seguros, tanto para garantir a restauração do projeto ou o pagamento da dívida.

Senna e Michel (2006), sobre a questão o risco em financiamentos de projetos baseados em parcerias público-privadas, comentam que a alocação do risco consiste em tarefa complexa e difícil, que implica, necessariamente, em negociação, variando o nível de risco, inclusive, com o tempo. Destacam, ainda, que o sucesso dos projetos tem sido caracterizado por uma clara definição do compartilhamento de riscos entre os setores público 
e privado, que geralmente possui mais eficiência quanto ao gerenciamento de riscos e responsabilidades comerciais, tais como aquelas relacionadas com a construção, operação e financiamento. Por outro lado, ressaltam os autores que a maioria dos projetos de transporte depende da participação pública em áreas de aquisição de "direito de passagem", riscos políticos e, em alguns casos, a participação pública na alocação de riscos em financiamentos abarca questões referentes à incerteza inerente ao tráfego e os correspondentes riscos de receita.

Ressaltam ainda Senna e Michel (2006) que o financiamento de projetos tem funcionado melhor quando empresas experientes e bem capitalizadas apresentam suficiente conhecimento acerca das formas e políticas de pedágio, assumindo para si os riscos de construção e em alguma proporção dos riscos de tráfego ${ }^{6}$.

Senna e Michel (2006), especificamente no que se refere aos riscos de receita e tráfego, consideram que o risco de demanda representa o assunto principal em todos os projetos, pois mesmo existindo nível razoável de confiabilidade nas previsões, a demanda pode ser afetada dramaticamente em função da concorrência com outros modos ou instalações de transporte, causando alterações dos padrões atuais e das condições macroeconômicas.

Destacam os citados autores que os volumes de tráfego são muito sensíveis ao crescimento econômico e de renda, e o fracasso em reconhecer convenientemente esta relação é considerada como uma das principais razões pelas quais muitos projetos de rodovias pedagiadas têm fracassado ou concluído em penosas negociações. É atribuída à elevada elasticidade $^{7}$ da renda, especialmente para viagens de lazer, uma maior sensibilidade de projetos de PPPs para rodovias destinadas a concessões, às condições macroeconômicas.

Consiste em fato que, na última década, vários foram os projetos de rodovias destinadas à concessão que apresentaram sérios problemas devido ao excessivo otimismo (considerado comum em equipes de privatização!) que conduz à dramática superestimativa nos níveis de tráfego, sendo diversos os exemplos que podem ser citados que possuem relação com este problema (Flyvbjerg et al., 2003; apud Senna e Michel, 2006).

\section{CONSIDERAÇÕES FINAIS}

Considera-se que o esforço institucional do Estado na área da regulação visando estimular o ambiente competitivo, com a promoção da parceria público-privada em investimentos na infraestrutura de transportes, setor considerado como um dos maiores entraves ao crescimento econômico no Brasil se apresenta, portanto, merecedor da devida atenção por parte dos estudiosos que possuem interesse na área da análise econômica de projetos de investimento.

\footnotetext{
${ }^{6}$ O governo, segundo esta visão do tema dos riscos, assumiria efetivamente os riscos sob sua responsabilidade e propiciaria o aval ao aporte financeiro na forma de garantias, caso os níveis de tráfego nos primeiros anos do projeto se mostrem insuficientes.

${ }^{7}$ A motorização e os veículos-quilômetro tendem a incrementar-se mais rapidamente que os correspondentes incrementos de renda em uma região de influência para o projeto.
} 
Em relação à análise de viabilidade de investimentos em infraestrutura de transportes mediante a metodologia Project Finance, cabe ressaltar que a Administração Pública, funcionando como promotora do projeto, estaria interessada no resultado prático do mesmo, relacionado com a satisfação de uma necessidade (aumentar os benefícios sociais, equilibrar o desenvolvimento ou a prestação de determinado serviço), processo este que estará sob a gestão da SPE mediante o modelo BOT (built, operate and transfer), ocorrendo ao final do período de concessão a transferência da titularidade (devolução) da infraestrutura ao Estado.

Caberá ao Estado, então, através do agente regulador, a atividade de autorizar e conceder à SPE a gestão do projeto, havendo a transferência de grande parte do risco para a responsabilidade desta sociedade. Para que este risco possa ser adequadamente distribuído entre as diversas partes, atividade considerada como complexa, são necessários para a composição do sistema vários assessores externos (jurídicos, financeiros, engenharia, meioambiente...), para que sejam convenientemente avaliados os condicionantes do entorno para a minoração do risco a níveis de aceitação adequados.

Aos assessores jurídicos caberá a tarefa da avaliação das interferências no projeto decorrentes do marco legislativo e fiscal, sendo o impacto ambiental do projeto avaliado mediante a participação dos assessores ambientais. Os assessores de engenharia e financeiros estariam encarregados, respectivamente, pela avaliação técnica do projeto (valoração dos riscos e custos derivados de sua construção) e pela valoração dos riscos econômicos e financeiros do projeto.

Também consiste em ponto de destaque no trabalho o esforço institucional no resgate do planejamento estatal em investimentos na infraestrutura de transportes, com a apresentação de iniciativas dirigidas para fazer frente aos desafios que o Brasil tem enfrentado para manter níveis de crescimento econômico que propiciem sustentabilidade do desenvolvimento da economia nacional, relacionados, em grande monta, com problemas na infraestrutura de transportes e de logística.

A demanda reprimida por investimentos no setor, tendo em vista às necessidades de dotar o País de um sistema de transporte adequado, após duas décadas de baixos níveis de investimento, em virtude da crise financeira e fiscal ao longo dos anos 80 , tendo o país passado por dificuldades crescentes de acessar os mercados internacionais de crédito, induz à postura governamental da busca pelo resgate da prática do planejamento dos investimentos. O governo, desde 2007, vem mobilizando recursos públicos e privados para aumentar os investimentos em infraestrutura, tendo sido criado o Programa de Aceleração do Crescimento (PAC) com a premissa de que o setor público estaria à frente da retomada dos investimentos em infraestrutura.

Entretanto, por força das restrições fiscais do Estado e baixa capacidade de execução dos projetos, os investimentos em infraestrutura tem-se situado em torno de $2 \%$ do PIB $(0,5 \%$ no setor de infraestrutura de transportes), o país está abaixo do mínimo necessário e distante dos competidores, que investem sistematicamente acima de $4 \%$ do PIB, chegando a alguns casos a 10\% do PIB. Desde o advento da Constituição Federal de 1988 (CF/88), com a proibição da vinculação de receita de impostos a órgãos, fundos ou despesas 
predeterminadas, a infraestrutura de transportes em geral (especialmente a rodoviária) depende quase exclusivamente de recursos ordinários da União. No caso das rodovias, com a crise fiscal dos governos estaduais e federal, o sistema foi contemplado com baixos níveis de investimentos públicos, insuficientes até para a sua manutenção, com a conseqüente deterioração das vias.

Como forma de compensação, a própria CF/88 (Art. 175) previu o restabelecimento da possibilidade de empresas privadas investirem no setor, tendo a União iniciado o Programa de Concessão de Rodovias Federais para a iniciativa privada em 1995 (Lei no. 8.987/95). Para viabilizar a participação privada em empreendimentos com pouca ou nenhuma rentabilidade financeira, o governo promulgou, em dezembro de 2004, a Lei no. 11.079 que regulamentou o estabelecimento de parcerias público-privadas visando ampliar a capacidade da Administração Pública, por meio da parceria com a iniciativa privada, em prover serviços de infraestrutura além de garantias que visam à maior atração de investimentos, no intuito de reduzir as deficiências no financiamento das obras necessárias, já que desobriga o Estado de arcar sozinho no setor de infraestrutura.

Recentemente, como forma de promover a continuidade ao processo de reestruturação do setor da infraestrutura de transportes nacional, considerado como um dos principais gargalos para o crescimento econômico do país, o governo federal, mediante o lançamento do "Plano Nacional de Logística: Rodovias e Ferrovias" criou a Empresa de Planejamento e Logística com a Medida Provisória no $576^{8}$, no objetivo estimular os investimentos em infraestrutura para reduzir os gargalos ao escoamento, reduzindo o custo de se produzir no país, em parceria com empresas do setor privado por meio de concessões, na intenção de fomentar a diminuição do "Custo Brasil" e melhorar as condições de transportes e logística para que o Brasil consiga melhor atender às demandas do mercado interno e competir no externo.

\section{REFERÊNCIAS BIBLIOGRÁFICAS}

1. ALLEN, G. Economic Policy and Statistics Section. Research Paper 03/79. Ed. House of Commons Library. London, 2003.

2. DALBEM, M. C.; BRANDÃO, L. e MACEDO-SOARES, T. D. A avaliação econômica de projetos de transporte: melhores práticas e recomendações para o Brasil. Rev. de Adm. Pública. Rio de Janeiro 44(1): 87-117, Jan./Fev., 2010.

3. DEL BO. Recent Advances in Public Investment, Fiscal Policy and Growth. Universitá degli Studi di Milano, Ottobre 2009 (Working Paper n. 2009-25).

4. DELFOUR, O. (2010). Metodologia de Rating para a infra-estrutura e Project Finance. Infra-estrutura Global \& Project Finance, Janeiro de 2010.

5. FLYVBJERG, B.; BRUZZELIUS, N. e ROTHENGATTER, W. Megaprojects and Risk - An Anatomy of Ambition. Ed. Cambridge University Press, 2003.

6. GARTNER, Ivan Ricardo. Análise de Projetos em Bancos de Desenvolvimento: Proposição de um Modelo de Análise. Dissertação de Mestrado. Programa de Pós-Graduação em Engenharia de Produção. UFSC, 1995.

\footnotetext{
${ }^{8}$ Altera as Leis no 10.233 , de 5 de junho de 2001, e no 12.404, de 4 de maio de 2011, para modificar a denominação da Empresa de Transporte Ferroviário de Alta Velocidade S.A. - ETAV para Empresa de Planejamento e Logística S.A. - EPL, e ampliar suas competências.
} 
7. GOSPODINI, A. Urban development, redevelopment and regeneration encouraged by transport infrastructure projects: the case study of 12 European cities. European Planning Studies, v. 13, n. 7, Oct. 2005.

8. GUSSO, Divonzir Arthur. Programa Avaliação Socioeconômica de Projetos - Módulo 1: Elementos de Avaliação de Projetos. ENAP, 2010.

9. HANOUSEK, Janos \& Evzen KOCEND. Public investment and growth in new EU member states: an overview. Universitá degli Studi di Milano/DSEAS, Ottobre 2009 (Working Paper n. 2009-23) (captado em IDEAS: http://ideas.repec.org ).

10. IRWIN, T. (2007). Government Guarantees: Allocating and Valuing Risk in Privately Financed Infrastructure Projects. The International Bank for Reconstruction and Development - The World Bank, Washington D.C.

11. IZQUIERDO, R. e VASSALLO, J.M. (2005). Nuevos Sistemas de Gestión y Financiación de Infraestructura de Transportes. Ed. Colegio de Ingenieros de Caminos, Canales y Puertos, Madrid.

12. JONES-LEE, M. W.; HAMMERTON, M.; PHILIPS, P. R. The value of safety: results of a national survey. The Economic Journal, v. 95, n. 377, p. 49-72, 1985.

13. MUNNE, Alicia. Policy Watch - Infrastructure Investment and Economic Growth, in Journal of Economic Perspectives. Vol. 6, N 4, Fall 1992, pp. 189-198.

14. ROSSETTI, José Paschoal. Introdução à Economia. $11^{\text {a }}$ ed. São Paulo: Atlas, 1985. SAMUELSON, P. The pure theory or public expenditure. The Review of Economics \& Statistics, v. 36, n. 4, p. 387-389, Nov. 1954.

15. SENNA, L.A.S. e MICHEL, F.D. Rodovias Auto-Sustentadas: O Desafio do Século XXI. Ed. CLA Cultural. São Paulo, 2006.

16. World Bank. Independent Evaluation Group (IEG). Impact evaluation, 2007.

17. _. TRN-15. Transport Notes. Valuation of time savings. 2005.

18. __. Handbook on economic analysis of investment operations. WBH. May 1996. 